\title{
Laboratory Test Reference Range Indicator
}

National Cancer Institute

\section{Source}

National Cancer Institute. Laboratory Test Reference Range Indicator. NCI Thesaurus.

Code C83094.

A indication that a laboratory test result lies within normal parameters. 